\title{
Interference Control in Children with Attention Deficit/Hyperactivity Disorder
}

\author{
Rosa van Mourik • Alky Papanikolau • \\ Joyce van Gellicum-Bijlhout • \\ Janneke van Oostenbruggen • Diane Veugelers • \\ Annebeth Post-Uiterweer • Joseph A. Sergeant • \\ Jaap Oosterlaan
}

Published online: 18 October 2008

(C) The Author(s) 2008. This article is published with open access at Springerlink.com

\begin{abstract}
The view that Attention Deficit/Hyperactivity Disorder (ADHD) is associated with a diminished ability to control interfference is controversial and based exclusively on results of (verbal)-visual interference tasks, primarily the Stroop Color Word task. The present study compares medication-naïve children with ADHD $(n=35$ and $n=51$ in Experiments 1 and 2, respectively) with normal controls ( $n=26$ and $n=32$, respectively) on two interference tasks to assess interference control in both the auditory and the visual modality: an Auditory Stroop task and a Simon task. Both groups showed reliable but equal degrees of interference on both tasks, suggesting that children with ADHD do not differ from normal controls in their ability to control interference in either modality.
\end{abstract}

Keywords Attention deficit/hyperactivity disorder. ADHD · Interference control · Auditory Stroop task · Simon task

Interference control encompasses both the ability to inhibit selectively the processing irrelevant information and the ability to inhibit automatic response tendencies in order to perform a more controlled action. Although there is a

\footnotetext{
R. van Mourik $(\bowtie) \cdot J$. A. Sergeant $\cdot$ J. Oosterlaan

Department of Clinical Neuropsychology, VU University,

Van der Boechorststraat 1,

1081 BT Amsterdam, The Netherlands

e-mail: R.van.mourik@psy.vu.nl

A. Papanikolau $\cdot$ J. van Gellicum-Bijlhout .

J. van Oostenbruggen $\cdot$ D. Veugelers $\cdot$ A. Post-Uiterweer

Academic Centre for Child and Adolescent Psychiatry De Bascule,

University of Amsterdam,

Amsterdam, The Netherlands
}

relation between inhibition and interference control functions (Friedman and Miyake, 2004), not all inhibitionrelated functions are equally impaired in individuals with ADHD. While the preponderance of the evidence indicates that individuals with ADHD are impaired on response inhibition tasks, (Alderson et al. 2007; Lijfijt et al. 2005; Oosterlaan et al. 1998), the evidence for a deficit in interference control in ADHD is less clear. Interference control is an important aspect of 'executive functioning', which is incorporated in influential theoretical models of ADHD (Barkley 1997; Pennington and Ozonoff 1996; Sergeant 2005; Sonuga-Barke 2003).

Interference control is typically measured with tasks that elicit conflict between an automatic response and a more controlled action, such as the Stroop Color-Word task (Stroop 1935; see for review MacLeod 1991). Interference control in ADHD is recently addressed in as much as six meta-analyses (Fraizer et al. 2004; Hervey et al. 2004; Homack and Riccio 2004; Lansbergen et al. 2007; Schwartz and Verheaghen 2008; Van Mourik et al. 2005) with mixed results: Mean weighted effect sizes (Cohen's d) ranged from 0.15 (Hervey et al.) to 0.54 (Frazier et al.). These inconsistent results might be attributable to different and even incorrect quantification methods of the interference score (Lansbergen et al.). All meta-analyses were almost exclusively based on studies that employed the Stroop Color-Word task to measure interference control.

Regions of the brain that are involved in interference control include the anterior cingulate cortex and the dorsolateral prefrontal cortex (MacLeod and MacDonald 2000; Peterson et al. 2002). Volumetric abnormalities in these regions have been shown in individuals with ADHD (Seidman et al. 2006) and patterns of brain activation during interference tasks differ between ADHD groups and 
normal control groups (Bush et al. 1999; Schulz et al. 2005; Vaidya et al. 2005; Zang et al. 2005). Surprisingly, at the performance level, no weakness in interference control was found in ADHD groups in these studies. This might be due to the very small sample size (eight to ten participants per group) employed in these studies. Another possibility is that the presumed deficit in interference control in ADHD is minor or only present in a small subsample.

The Stroop Color-Word task is an elegant task to investigate interference control but has limitations in research on ADHD. Children with ADHD encounter difficulties with the baseline conditions (color naming and word reading) of the Stroop Color-Word task, probably caused by a rapid naming deficiency (Tannock et al. 2000). Blue-yellow color perception problems may contribute to slower color naming (Banaschewski et al. 2006). Another limitation is that automatic reading skill is a prerequisite for the Stroop Color-Word task but reading disability tends to co-occur in approximately $20 \%$ of the individuals with ADHD (Del'Homme et al. 2007). Therefore, alternative methodologies are needed to answer the question whether children with ADHD have a deficit in interference control.

One alternative may be a Flanker task (Eriksen and Schultz, 1979), in which the individual is required to respond to a central arrow that is flanked by arrows that point in the same direction (congruent condition) or in the opposite direction (incongruent condition). Various studies (see for example Crone et al. 2003; Jonkman et al. 1999; Scheres et al. 2004; Van Meel et al. 2007) indicate that children with ADHD are more sensitive to interference in Flanker tasks: Children with ADHD make more errors or disproportionally slow down in the incongruent condition compared with the congruent condition. Negative findings for group differences have also been reported (for example Booth et al. 2007). A possible confounding influence in the Flanker task is that children with ADHD have more problems restricting their visual attention to a limited spatial area resulting in more interference from the incongruent flankers. In support of this, Crone et al. (2003) showed that, in contrast to normal control children, children with ADHD slowed down more, when congruent flankers were introduced compared with a condition without flankers. Selective attention deficits in ADHD have not only been shown in the visual domain, but also in the auditory domain (Brodeur and Pond 2001; Jonkman et al. 1997), which suggests that the ability to focus attention and ignore irrelevant information is a more general problem in ADHD.

To determine the nature of the presumed deficit in interference control in ADHD, it is important to know whether this deficit is still present when the ability to restrict one's attention to a limited area is controlled. This can be achieved with interference tasks in which the conflicting information is incorporated in the stimulus itself, such as for example in a Simon task (Simon 1990) or in a Counting Stroop task (Bush et al. 1998). In these tasks, the degree to which the conflicting information is processed is not partly dependent on the ability to focus attention, but relies solely on the ability to suppress the processing of conflicting information. Such interference tasks have been used in various behavioral and functional imaging studies of ADHD with mixed results. Most studies (Albrecht et al. 2008; Bush et al. 1999; Drechsler et al. 2005; Rubia et al. 2007; Schulz et al. 2005; Smith et al. 2006; Zang et al. 2005) reported no specific behavioral deficit in interference control in ADHD, while only one study reported specific difficulties in interference control in an ADHD group (Kaufman and Nuerk 2006).

The failure to find group differences in interference control at the performance level in functional imaging studies (Bush et al. 1999; Schulz et al. 2005; Smith et al. 2006; Zang et al. 2005) might be due to small sample sizes. The power in fMRI studies is enough to find large effects, typical for functional imaging results, but not for medium or small effects, that are typically found in performance studies. Drechsler et al. (2005) used a very fast stimulus presentation rate $(100 \mathrm{~ms})$ and an auditory warning preceded all stimuli. This triggered impulsive responding, resulting in more errors in the ADHD group, hence possibly obscuring the interference effect. Children with ADHD also showed increased error rates to both congruent and incongruent trials in the study of Rubia et al. 2007. These issues make the negative findings for group differences in interference control less reliable.

Another limitation of these studies is that interference control was assessed only in the visual domain. At this point, nothing is known about the effects of stimulus modality on interference control in children with ADHD. However, two recent meta-analyses, one on response inhibition (Alderson et al. 2007) and the other on working memory (Martinussen et al. 2005) in ADHD show that stimulus modality is an important moderator of impaired task performance. Performance deficits were more pronounced in visual tasks than in auditory tasks. Because interference control is related to both response inhibition (Friedman and Miyake 2004) and working memory (Kane and Engle 2003), it is plausible that interference control in ADHD is more affected in the visual domain than the auditory domain. Therefore, this study assessed interference control in both the auditory and visual modality in children with ADHD. Two different tasks are employed: a newly developed Auditory Stroop task (adapted from McClain 1983) to assess interference control in the auditory domain and a Simon task (Simon 1990) to measure interference in the visual spatial domain. An advantage of both tasks is that they are independent of reading ability and that they provide a relative 'pure measure of interference control' in 
which the interfering information is integrated in the stimulus itself, controlling for selective attention deficits.

\section{Experiment 1}

Methods

\section{Participants and Selection Procedure}

Thirty-five children with ADHD were recruited through a university affiliated outpatient clinic specialized in the assessment and treatment of ADHD. Twenty-six control children were recruited through local primary schools. All children were between the ages of 8 years and 12 years. Parents completed a written informed consent prior to the study, which was approved by the local ethical committee. The children with ADHD were all identified as meeting the DSM-IV criteria (APA 1994) for ADHD by a multidisciplinary team of professionals. They had never used psychostimulant medication previously.

Assessment included the Dutch version of the Disruptive Behavior Disorder rating scale (DBD; Oosterlaan et al. 2000; Pelham et al. 1992), completed by parents and teachers of all children. Parents of the children with ADHD were also administered the ADHD, ODD (Oppositional Defiant Disorder) and CD (Conduct Disorder) sections of the Diagnostic Interview Schedule for Children (DISC-IV; Shaffer et al. 2000), which generates DSM-IV diagnoses. IQ was estimated with two performance and two verbal subtests of the Dutch version of the Wechsler Intelligence Scale for Children, third edition (Kort et al. 2002; Weschler 1991): Picture Arrangement, Block Design, Arithmetic, and Vocabulary. Reading ability in the ADHD group was assessed with a standard Dutch reading test, the ThreeMinutes-Test (DMT; Brus and Voeten, 1973). Comorbid reading problems were defined as a standardized score below the 10th percentile. These stringent criteria were applied because there might be a negative relation between reading skill and interference (Protopapas et al. 2007).

The children with ADHD entered the study, if they met the DSM-IV criteria for ADHD using the DISC-IV and, in addition, obtained parent and teacher ratings above the 90th percentile on the Inattention and/or the Hyperactivity/ Impulsivity scales of the DBD. Normal controls were required to have scores below the subclinical threshold (90th percentile) on all DBD scales. The mean percentile score for the normal control group was around the 30th percentile, which clearly indicates that the normal controls were free of ADHD related symptoms. An estimated IQ score above 70 was required for all children and they had to be free of any neurological, sensory, or motor impairment or any developmental psychiatric disorder other than
ADHD, ODD, CD or dyslexia. All children had normal or corrected to normal vision and children with hearing problems were excluded from the experiments. Subject characteristics are summarized in Table 1. Groups did not differ in age, male/female ratio or IQ.

\section{Auditory Stroop Task}

The Auditory Stroop task (McClain 1983) was adapted for Dutch children. The task consisted of two experimental trial types (congruent and incongruent) and neutral control trials. All stimuli were binaurally presented through headphones at a high $(734 \mathrm{~Hz})$ and a low $(167 \mathrm{~Hz})$ pitch at approximately $60 \mathrm{~dB}$. The child was instructed to respond to the pitch by pressing one of two response buttons. Half of the participants responded with their left hand to the high stimuli and with their right hand to the low stimuli, and the other half vice verse. The congruent trial types were the Dutch words for 'high' and 'low', presented at a respectively high and low pitch. In the incongruent trials, the word 'high' was presented at a low pitch and the word 'low' at a high pitch. In order to control for possible facilitation effects, two control conditions were included: tones presented at a low and high pitch as well as the Dutch words for 'old' and 'young', presented at a low and high pitch. The neutral words 'old' and 'young' were chosen as a neutral control trials because the words 'high', 'low', 'old' and 'young' are all adjectives and their frequency in spoken Dutch is comparable (CGN, Corpus Spoken Dutch 2004). A picture of an ear was shown at the centre of a computer screen and was present throughout the task. It then blinked once in a blue color for $300 \mathrm{~ms}$ to prime the child to pay attention. The stimuli were presented $500 \mathrm{~ms}$ after the prime with a duration of $720 \mathrm{~ms}$. The interstimulus interval (ISI) was $4,000 \mathrm{~ms}$. This interval is relatively long to prevent an impulsive response strategy, such as responding at the first syllable of the word. Because the word meaning interferes with pitch, the participant was required to listen to the word; otherwise, the word could not interfere with the pitch. The task consisted of 256 trials (64 per condition) presented in random order and divided into 4 blocks. Although interference effects are stronger if there are more congruent trials compared to incongruent trials, this experiment consisted of an equal proportion of congruent and incongruent trials. The reason for this was that, if the majority of the trials had been congruent, a failure to maintain the goal of the task (respond to the pitch) might occur, leading to more errors on incongruent trials. It has been shown that individuals with low working memory capacity are especially sensitive to this manipulation compared to individuals with high working memory capacity (Kane and Engle 2003). Children with ADHD typically have lower working memory capacity compared 
Table 1 Participant Characteristics Experiment 1

\begin{tabular}{|c|c|c|c|c|c|}
\hline \multirow[t]{3}{*}{ Measure } & \multicolumn{5}{|l|}{ Group } \\
\hline & \multicolumn{2}{|c|}{$\operatorname{ADHD}(n=35)$} & \multicolumn{2}{|c|}{$\mathrm{NC}(n=26)$} & \multirow{2}{*}{$\frac{\text { Group Comparison }}{F(1,59)}$} \\
\hline & $M$ & $S D$ & $M$ & $S D$ & \\
\hline Boys/Girls & $26 / 9$ & - & $19 / 7$ & - & $0.5^{\mathrm{a}}$ \\
\hline Age (in months) & 120 & 16 & 121 & 14 & 0.2 \\
\hline IQ & 99 & 11 & 103 & 16 & 1.7 \\
\hline \multicolumn{6}{|l|}{ DBD Parents } \\
\hline Inattention & 17.0 & 5.2 & 1.9 & 2.2 & $192.8 * *$ \\
\hline Hyperactivity/Impulsivity & 14.0 & 5.0 & 1.3 & 1.4 & $157.1 * *$ \\
\hline ODD & 6.7 & 4.6 & 0.7 & 1.2 & $41.7 * *$ \\
\hline $\mathrm{CD}$ & 1.0 & 2.0 & 0.04 & 0.2 & $6.1^{*}$ \\
\hline \multicolumn{6}{|l|}{ DBD Teacher } \\
\hline Inattention & 17.7 & 4.3 & 1.1 & 1.7 & $321.7 * *$ \\
\hline Hyperactivity/Impulsivity & 15.4 & 7.3 & 0.7 & 1.1 & $95.7 * *$ \\
\hline ODD & 7.0 & 6.7 & 0.5 & 1.3 & $22.5 * *$ \\
\hline $\mathrm{CD}$ & 2.3 & 3.8 & 0.1 & 0.3 & $7.7^{*}$ \\
\hline DISC-IV Subtypes & \multicolumn{5}{|c|}{15 ADHD-Combined subtype } \\
\hline (ADHD-group) & \multicolumn{5}{|c|}{15 ADHD-Inattentive subtype } \\
\hline & \multicolumn{5}{|c|}{5 ADHD-Hyperactive subtype } \\
\hline Comorbidity & \multicolumn{5}{|c|}{9 Oppositional Defiant Disorder } \\
\hline (ADHD-group) & \multicolumn{5}{|c|}{1 Conduct Disorder } \\
\hline & \multicolumn{5}{|c|}{8 Reading Problems } \\
\hline
\end{tabular}

Abbreviations: $\mathrm{ADHD}=$ Attention Deficit Hyperactivity Disorder, DBD $=$ Disruptive Behavior Disorder rating scale, DISC $=$ Diagnostic Interview Schedule for Children, $\mathrm{CD}=$ Conduct Disorder, $\mathrm{M}=$ Mean, $\mathrm{NC}=$ Normal Control, ODD $=$ Oppositional Defiant Disorder, $\mathrm{SD}=$ Standard Deviation.

${ }^{*} \mathrm{p}<0.05{ }^{* *} \mathrm{p}<0.001 ;{ }^{\mathrm{a}} \chi^{2}$

to normal controls (Martinussen et al. 2005). Therefore, this manipulation would pose an extra challenge for the ADHD group. Because the goal was to measure interference control as purely as possible, an equal number of trials in each condition was chosen. Pilot results showed that the task was too difficult for children younger than 8 years, hence only children older than 8 years were assessed.

Task instructions were displayed on the computer screen and were read aloud by the child or, if this was too difficult, the experimenter read out aloud the instructions. The children participated in one or two practice blocks, including twenty-four trials with feedback on each response, until the child fully understood the task requirements. After the practice session, the child was instructed to respond as accurately and as fast as possible to the pitch and to ignore the word meaning. The child was informed about his or her performance: mean reaction time, number correct and number of errors appeared on the screen after each block. The dependent variables were mean reaction time (MRT) and percentage of errors.

\section{Statistical Analyses}

Children responded slower to the tones than to the incongruent condition, which makes the tones unsuitable as a control condition. MRTs to the words 'old' and 'young' did not differ significantly from MRTs in the congruent condition, suggesting that there was no facilitation effect in this task. Therefore, only the congruent condition was compared with the incongruent condition. MRT was analyzed with a repeated measures ANOVA with one within subjects factor (condition: congruent-incongruent) and one between subjects factor (group: ADHD—normal controls). It was not possible to transform the percentage of errors to approach the normal distribution. Therefore, percentage of errors in the congruent and the incongruent condition were compared with a non-parametric Wilcoxon Rank test. Groups were compared with a Mann-Whitney U test on: (1) percentage of errors in the congruent condition, (2) percentage of errors in the incongruent condition, and (3) the difference in percentage of errors between the congruent and the incongruent condition (interference effect). All analyses were repeated removing those children with comorbid reading problems and the children with the inattentive subtype. The 10th percentile of the interference score (incongruent minus congruent for mean reaction time) was calculated for the normal control group. In order to test whether interference control might be deficient in a subsample of children with ADHD, the participants that had an interference score lower than this 10th percentile were 
counted in both groups. The relation between, on the one hand, hyperactivity/impulsivity and attention problems and, on the other hand, interference control was examined by computing correlations (Spearman) between the interference scores (incongruent minus congruent for MRT and percentage of errors) and the Inattention and Hyperactivity/ Impulsivity subscales of the DBD for both parent and teacher ratings. Two participants in the ADHD group who had a very low accuracy rate (below $60 \%$ ) were excluded from the study. The two excluded participants were not entered into the analyses nor represented in any of the data in this paper.

\section{Results}

Task and Group Performance

MRT and percentage of errors are displayed in Fig. 1. A highly significant condition effect $[F(1,59)=15.63, p<$ $\left.0.001, \eta^{2}=0.208\right]$ and a marginal significant group effect $\left[F(1,59)=3.95, p=0.051, \eta^{2}=0.062\right]$ were found for MRT: Children were on average $42 \mathrm{~ms}$ slower in the incongruent condition compared with the congruent condition and children with ADHD were on average 123 ms slower than their normal peers. No significant group by condition interaction occurred for MRT $[F(1,59)=0.43, p=0.512$, $\left.\eta^{2}=0.006\right]$. Significantly more errors were made in the incongruent condition than in the congruent condition $[Z=$ $\left.-3.43, p=0.001, \eta^{2}=0.183\right]$. Between group comparisons failed to reach significance for percentage of errors in the congruent condition, in the incongruent condition and for the difference in percentage of errors between the conditions $\left[U=325 p=0.056, \eta^{2}=0.066 ; U=364, p=0.183, \eta^{2}=0.017\right.$; $U=451, p=0.953, \eta^{2}=0.003$ respectively]. Two children (out of 35) scored below the 10th percentile on the interference score in the ADHD group and two children (out of 26) in the normal control group.

\section{Comorbid Reading Problems and ADHD Subtype}

To control for the potentially confounding effect of comorbid reading problems, we reanalyzed the data removing those children with comorbid reading problems $(n=8)$. The marginal significant group difference for MRT became non-significant $\left[F(1,51)=2.87, p=0.096, \eta^{2}=\right.$ $0.039]$. None of the other results differed from the previous analyses in terms of significant and non-significant effects. In order to test if deficient interference control was only present in ADHD combined or hyperactive/impulsive subtype, we removed those children that were diagnosed as ADHD-inattentive subtype $(n=15)$ from the analysis. Again, the marginally significant group difference for MRT became non-significant $[F(1,44)=1.92, p=0.173$, $\left.\eta^{2}=0.042\right]$.

\section{Correlations}

In both groups, no significant correlations $(n=35$ in the ADHD group and $n=26$ in the normal control group) were found between parent and teacher ratings on the DBD (Inattention and Hyperactivity/Impulsivity subscales) and the interference scores (MRT and percentage of errors): $r \mathrm{~s}$ ranged between -0.24 and 0.31 , all $p \mathrm{~s}>0.085$.
Fig. 1 Mean reaction time and percentage of errors (with standard deviations) in the auditory stroop task for the normal control and ADHD group

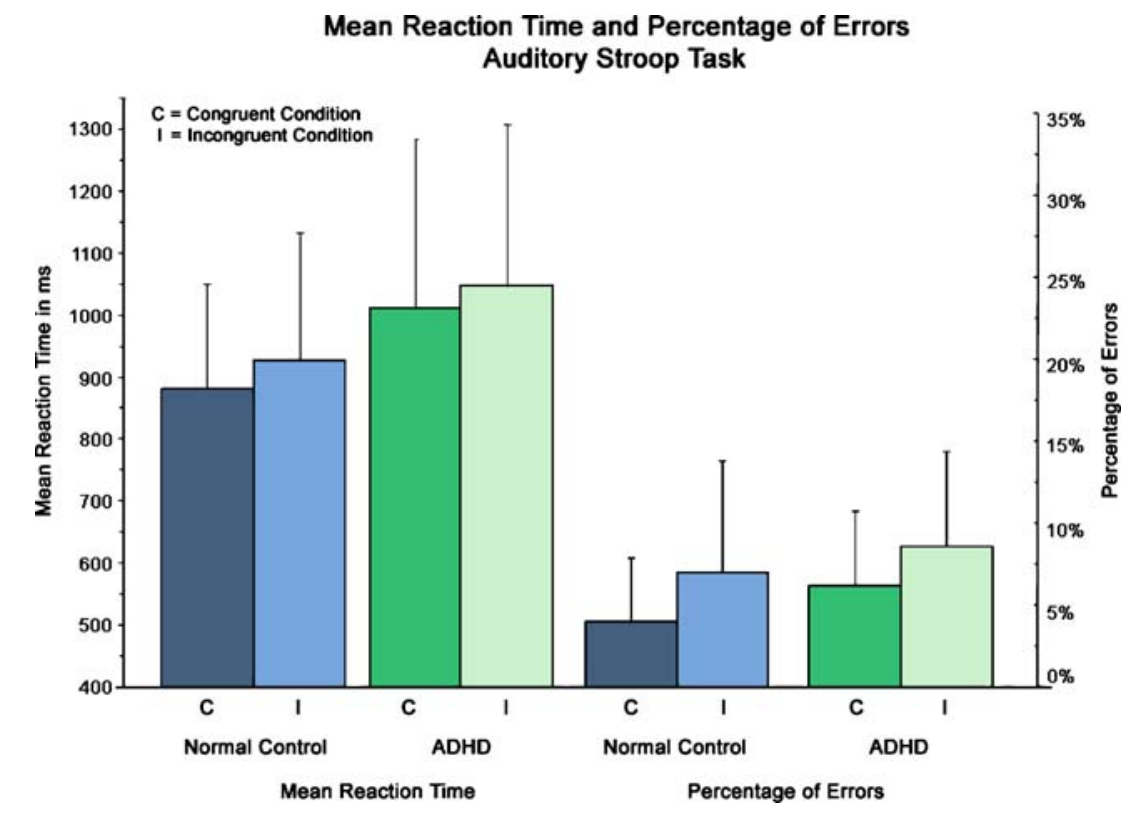




\section{Experiment 2}

To confirm and extend the findings of Experiment 1, a second experiment was performed to investigate interference control in the visual-spatial domain. In the second experiment, the Simon task (Simon 1990) was used and adapted for children from the age of 6 to measure interference control.

Methods

\section{Participants and Selection Procedure}

A subsample (28 children from the ADHD group and 20 children from the normal control group) that participated in Experiment 1 also participated in Experiment 2. An additional 23 children with ADHD and 12 normal controls were recruited according to the selection procedure employed in Experiment 1. All children were between the ages of 6 and 12 years old. Subject characteristics are summarized in Table 2. Groups did not differ in age, male/female ratio or IQ.

\section{Simon Task}

The Simon task consisted of two experimental trial types: congruent trials and incongruent trials. A fixation cross was present throughout the task. An arrow appeared $3 \mathrm{~cm}$ left or right of the fixation cross for $500 \mathrm{~ms}$. In the congruent condition, the arrow pointed to the same side as the side on which the arrow appeared and in the incongruent condition, the arrow pointed to the opposite side. The child was required to indicate the direction of the arrow with two response boxes and ignore the side on which the arrow appeared. The ISI was $2000 \mathrm{~ms}$ and 224 trials (112 congruent and 112 incongruent) were randomly presented over 4 blocks. The ISI was based on pilot work in which it was tried to evoke strong interference effects and to make the task suitable for even the youngest children in the groups. An equal proportion of congruent and incongruent trials was chosen for the same reason as in experiment 1 . The task was designed as a navigation game in which the children had to navigate a spaceship by indicating the direction of the arrow.

The testing procedure was the same as in Experiment 1, only the practice session differed in order to encourage children to respond fast. The children first practiced the task in three blocks of 12 trials with feedback ('correct', 'wrong', of ' too slow') on each response. In the first practice block, the children were required to respond to the stimulus within $2000 \mathrm{~ms}$, in the second practice block the response limit was $1750 \mathrm{~ms}$, and in the third practice block

Table 2 Participant Characteristics Experiment 2

\begin{tabular}{|c|c|c|c|c|c|}
\hline \multirow[t]{3}{*}{ Measure } & \multicolumn{5}{|l|}{ Group } \\
\hline & \multicolumn{2}{|c|}{$\operatorname{ADHD}(n=51)$} & \multicolumn{2}{|c|}{$\mathrm{NC}(n=32)$} & \multirow{2}{*}{$\frac{\text { Group Comparison }}{F(1,81)}$} \\
\hline & $M$ & $S D$ & $M$ & $S D$ & \\
\hline Boys/Girls & $41 / 10$ & - & $23 / 9$ & - & $0.8^{\mathrm{a}}$ \\
\hline Age (in months) & 107 & 20 & 106 & 20 & 0.1 \\
\hline IQ & 100 & 12 & 104 & 14 & 2.4 \\
\hline \multicolumn{6}{|l|}{ DBD Parents } \\
\hline Inattention & 15.9 & 4.8 & 1.9 & 2.3 & $240.1 * *$ \\
\hline Hyperactivity/Impulsivity & 15.4 & 6.3 & 1.8 & 2.1 & $140.0 * *$ \\
\hline ODD & 5.8 & 4.3 & 1.6 & 2.5 & $23.7 * *$ \\
\hline $\mathrm{CD}$ & 1.1 & 1.8 & 0.1 & 0.3 & $9.6^{*}$ \\
\hline \multicolumn{6}{|l|}{ DBD Teacher } \\
\hline Inattention & 16.5 & 5.1 & 1.7 & 2.0 & $238.0 * *$ \\
\hline Hyperactivity/Impulsivity & 15.9 & 7.8 & 1.0 & 1.4 & $115.0 * *$ \\
\hline ODD & 6.9 & 6.4 & 0.6 & 1.2 & $30.5^{* *}$ \\
\hline $\mathrm{CD}$ & 2.2 & 3.9 & 0.1 & 0.3 & $10.0^{*}$ \\
\hline DISC-IV Subtypes & \multicolumn{5}{|c|}{26 ADHD-Combined subtype } \\
\hline (ADHD-group) & \multicolumn{4}{|c|}{19 ADHD-Inattentive subtype } & 6 ADHD-Hyperactive subtype \\
\hline Comorbidity & \multicolumn{5}{|c|}{14 Oppositional Defiant Disorder } \\
\hline (ADHD-group) & \multicolumn{5}{|c|}{1 Conduct Disorder } \\
\hline & \multicolumn{5}{|c|}{8 Reading Problems } \\
\hline
\end{tabular}

Abbreviations: $\mathrm{ADHD}=$ Attention Deficit Hyperactivity Disorder, DBD $=$ Disruptive Behavior Disorder rating scale, DISC $=$ Diagnostic Interview Schedule for Children, $\mathrm{CD}=$ Conduct Disorder, $\mathrm{M}=$ Mean, $\mathrm{NC}=$ Normal Control, $\mathrm{ODD}=$ Oppositional Defiant Disorder, $\mathrm{SD}=$ Standard Deviation, ${ }^{*} \mathrm{p}<0.05{ }^{* *} \mathrm{p}<0.001 ;{ }^{\mathrm{a}} \chi^{2}$ 
the response limit was $1500 \mathrm{~ms}$, which was also the response limit in the experimental task. The dependent variables were mean reaction time (MRT) and percentage of errors.

\section{Statistical Analyses}

The statistical analyses were identical to those of Experiment 1 with the addition that correlations were computed between interference measures of the both experiments. One participant from the ADHD group who had a very low accuracy rate (below 60\%) was excluded from the analyses. None of the data of this participant is included in any section of this paper.

\section{Results}

\section{Task and Group Performance}

MRT and percentage of errors are summarized in Fig. 2. A highly significant condition effect was found for MRT $\left[F(1,81)=124.77, p<0.001, \eta^{2}=0.61\right]$ : Children were on average $54 \mathrm{~ms}$ slower in the incongruent condition than in the congruent condition. There was no significant group effect $\left[F\left(1,81=0.34, p=0.559, \eta^{2}=0.004\right]\right.$ or group by condition interaction $\left[F(1,81)=0.04, p=0.842, \eta^{2}<0.001\right]$. Significantly more errors were made in the incongruent condition than in the congruent condition $[Z=-7.86$, $\left.p<0.001, \eta^{2}=0.682\right]$. Between group comparisons failed to reach significance for percentage of errors in the congruent condition, in the incongruent condition and for the the difference in percentage of errors between the conditions $\left[U=662, p=0.146, \eta^{2}=0.024 ; U=813, p=0.974\right.$, $\eta^{2}=0.001 ; U=772, p=0.677, \eta^{2}=0.017$ respectively]. In the ADHD group, two children (out of 51) had an interference score below the $10^{\text {th }}$ percentile, whereas three children (out of 32) in the normal control group scored below the 10th percentile.

\section{Comorbid Reading Problems and ADHD Subtype}

All analyses were repeated removing 8 children from the ADHD group with comorbid reading problems and removing 19 children with ADHD-inattentive subtype. None of these results differed in terms of significant and non-significant effects from the results obtained in the entire group.

\section{Correlations}

In the ADHD group, no meaningful relationships were revealed between the interference measures and the subscales of the DBD: $r$ s ranged between -0.29 and 0.11 , all $p \mathrm{~s}>0.121$. In the normal control group, a significant correlation was found only between the interference score (percentage of errors) of the Simon task and the Inattention subscale of the teacher DBD: $r=0.52, p=0.002$. However, no such relation was found in the entire group. No meaningful relation was found between the interference scores of the Simon task and the Auditory Stroop task: $r \mathrm{~s}$ ranged between -0.17 and 0.11 , all $p \mathrm{~s}>0.486$.

\section{Discussion}

This study was conducted to address the question whether children with ADHD have a diminished ability to control
Fig. 2 Mean reaction time and percentage of errors (with standard deviations) in the Simon task for the normal control and ADHD group

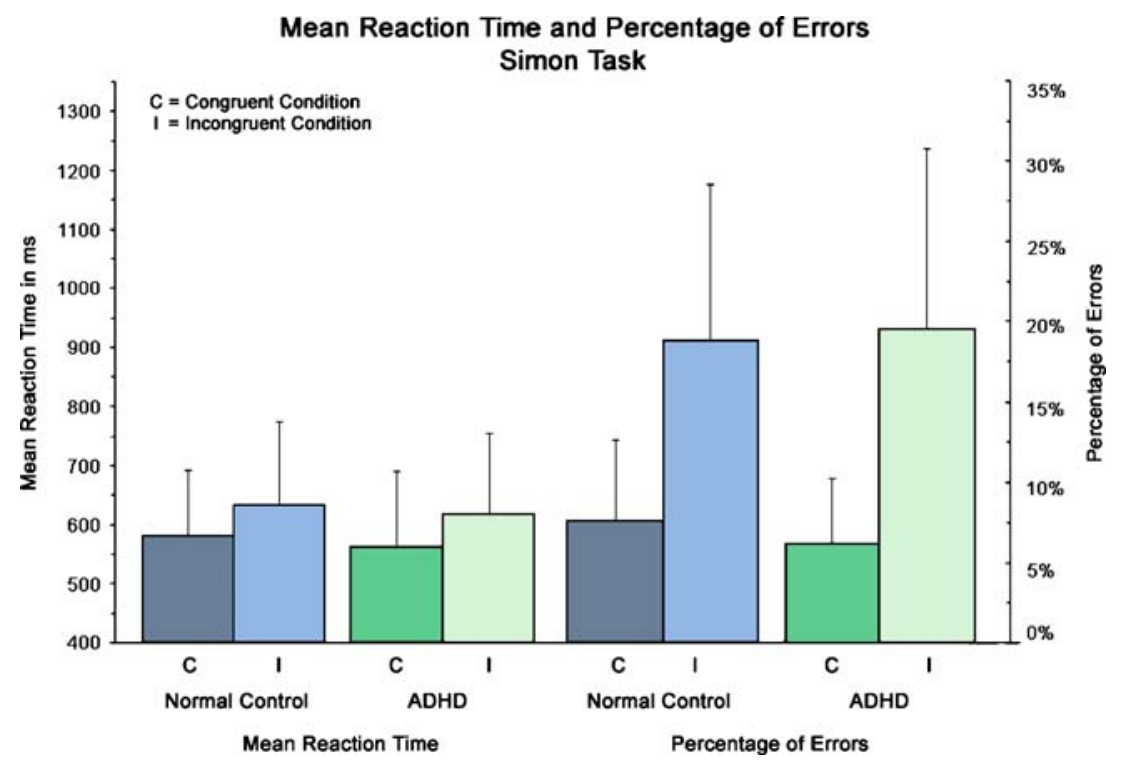


interference in both the auditory and the visual modality. The incongruent stimuli from the Auditory Stroop task and the Simon task evidently caused response conflict in both groups of children, thereby validating the tasks. This robust interference effect was reflected by increased response latency and an increased error rate in the incongruent condition compared with the congruent condition. The clear absence in both tasks of a significant group by condition interaction (F-values were below 1 and $p$-values above 0.50 ) convincingly demonstrates that both groups showed equal degrees of interference both in terms of reaction time and errors. These results seem to suggest that children with ADHD do not differ from normal controls in their ability to control interference and converge with recent empirical work that also reports the absence of a specific performance deficit in interference control in ADHD (Albrecht et al. 2008; Bush et al. 2008; Drechsler et al. 2005; Marchetta et al. 2008; Pritchard et al. 2007; Rubia et al. 2007). The finding that this effect was the same across two different interference tasks that differed in modality speaks to the reliability and generalizibility of the findings.

Surprisingly, the degree of interference in the Auditory Stroop task did not correlate with the interference effect in the Simon task. However, it has previously been found that even interference scores between different visual interference tasks do not correlate with each other (Stins et al. 2005). Possible explanations for the lack of correlations between different interference tasks may be due to modest reliability of interference scores in children (see Stins et al. 2005), because brain regions involved in interference control are not identical (Fan et al. 2003), or simply because different task characteristics such as modality (auditory versus visual) or task pace.

Inattention, as rated by the teacher, correlated with the interference score of the Simon task, but only in the normal control group. However, this result should be interpreted with caution, because one third of the children in the normal control group received a score of 'zero'on this subscale, and this relation was not found in the entire group. The relationship between neurocognitive deficits and behavioral problems is a complicated one and probably dependent on multiple factors such as for example motivation and cognitive strategies to compensate for problems to regulate behavior. Recent models (Sergeant 2005; Sonuga-Barke 2003; Willcutt et al. 2008) emphasize that there is not a single core deficit in ADHD, but rather multiple pathways that may lead to the diverse attentional and behavioral problems that characterize this heterogeneous disorder. In this study, there was no evidence that a subgroup of children with ADHD showed poorer interference control. This finding indicates that interference control per se is presumably not one of the pathways that leads to attentional and behavioral problems in ADHD.
Furthermore, the results did not change if children with the inattentive subtype were excluded from the analyses. Thus, a deficit in interference control does not seem present in the ADHD group as a whole, nor in the combined or hyperactive-impulsive subtype. These results are in line with previous work that failed to find group differences on neuropsychological profiles between children with the inattentive subtype and the combined subtype (Chhablidas et al. 2001).

A remarkable finding was that children with ADHD responded slower than normal controls in the Auditory Stroop task, but not in the Simon task. This finding is in contrast with previous research (Alderson et al. 2007; Martinussen et al. 2005) where children with ADHD were less impaired on auditory tasks compared to visual tasks. It is possible that the faster event rate in the Simon task (ISI was $2000 \mathrm{~ms}$ ) was more arousing for children with ADHD than the slow pace of the Auditory Stroop task (ISI was $4000 \mathrm{~ms}$ ). It has been repeatedly found that performance of children with ADHD is more impaired if a long ISI is used (Scheres et al. 2001; Wiersema et al. 2006; see Sergeant et al. 1999 for an explanation of event rate effects in terms of the cognitive energetic model). Another possibility could be that an auditory task poses a greater challenge to the attentional resources of children with ADHD: It might be more difficult to keep attention focused on what they hear as opposed to keeping attention focused on a computer screen. However, if the inattentive subtype or children with ADHD and comorbid reading problems were removed from the analyses, there were no significant differences in response speed on the Auditory Stroop task.

The present study further clarifies the controversy on interference effects in ADHD and sheds some light on the question under what conditions children with ADHD demonstrate deficits in interference control. Although there might be a small deficit in interference control, as measured by the Stroop Color-Word task (Carter et al. 1995; Lansbergen et al. 2007; Van Mourik et al. 2005), this finding does not seem to generalize to other interference tasks such as the Simon task and the Auditory Stroop task. It should be noted that in our tasks as well as in the Stroop Color-Word task, the interfering information was incorporated in the stimulus, thus both conflicting and nonconflicting aspects of the stimulus need to be processed, when the stimulus is perceived, just as in the classic Stroop Color-Word task. The current interference tasks measured the ability to suppress the processing of the irrelevant information and automatic response tendencies. The important ability to focus on what is relevant and ignore irrelevant surrounding information (crucial in Flanker tasks) was not addressed here. Deficits in this important and related aspect of information processing might be present in $\mathrm{ADHD}$, as is shown by impaired performance on Flanker 
tasks (Crone et al. 2003; Jonkman et al. 1999, Scheres et al. 2004; Van Meel et al. 2007). It has been shown that children with ADHD are less sensitive to the nature of distracters (incongruent or neutral) than normal controls, but slow down more than normal controls when distracters were introduced (Brodeur and Pond 2001; Crone et al. 2003). However, distraction that is not conflicting and unrelated to the task may even have beneficial effects on task performance of children with ADHD, possibly by increasing their arousal to an optimal level (Van Mourik et al. 2007). These results indicate that the extent to which irrelevant information disrupts or improves performance is task or situation dependent and that dealing with response conflict that is elicited by incongruent stimuli per se is unlikely to be disrupted in ADHD.

As noted in the introduction, the neural networks involved in the suppression of interference on various tasks have been shown to differ not only in childhood ADHD (Konrad et al. 2006; Vaidya et al. 2005; Zang et al. 2005), but also in adolescence (Schulz et al. 2005), and adulthood (Bush et al. 1999; Bush et al. 2008), despite participants with ADHD showing similar task performance compared to normal controls. Increased activation in the fronto-striatal network during interference suppression has been interpreted as reflecting possible compensatory processes, or a greater effort to control interference. These compensatory processes may not be specific for interference control per se, but may be recruited by individuals with ADHD, when they perform difficult cognitive tasks that measure executive functioning (Fassbender and Schweitzer 2006). Thus, although our results do not support the theory that children with ADHD suffer from a core deficit in interference control, we cannot exclude the possibility that interference control is more effortful in children with ADHD and that performance measures alone may not be sufficiently sensitive to detect difficulties in interference control.

\section{Limitations}

A limitation of this study is that the interference effects in our tasks are not as strong as in the classical Color-Word Stroop. Because the tasks consisted of equal numbers of incongruent and congruent trials, interference effects may have been less pronounced compared to other designs. However, the effect sizes of the interference effects were large in both tasks, thus the Auditory Stroop task and the Simon task are sensitive measures of interference control. Another limitation is that, as opposed to the classical ColorWord Stroop, no facilitation effects were found in the Auditory Stroop task. All children responded slower on one of the initial control conditions in the Auditory Stroop task (tones) compared to the other conditions. Spoken language is probably processed faster than tones because children are so familiar with speech. This could make judging tones more difficult, and therefore unsuitable as a neutral control condition. In the Simon task, no neutral control condition was included, thus there was no control for possible facilitation effects. The Auditory Stroop task was only assessed in children above the age of 8 years, because pilot results showed that this task was too difficult for younger children. This is a limitation of the task and it suggests that it may be difficult for younger children to form an association between a word and the pitch or use their former semantic knowledge on the words. The concepts 'high' and 'low' may still pose a challenge for some of the children included in the study, resulting in overall slower reaction times or increased error rates in these children.

\section{Clinical Implications and Future Directions}

Apart from a small deficit on the Stroop Color-Word task, children with ADHD do not demonstrate deficits on interference tasks in which the interfering information is integrated in the stimulus. These measures of interference control are unrelated to ratings of inattentive and hyperactive/ impulsive behaviour in ADHD. Therefore, we advise against the use of these sorts of interference tasks in clinical practice as an aid in characterizing the deficits of children with ADHD. However, several issues warrant future research. Most importantly, the relation between aberrant brain activity, on the one hand, and normal performance on interference tasks on the other hand, needs to be elucidated. It is important to determine the factors contributing to this paradoxal result. It might be possible that children with ADHD demonstrate a deficit in interference control only when task demands are high. For example, a very low proportion of incongruent trials or a switch manipulation could be a fruitful approach. Thus, although interference control per se seems to be intact in ADHD, it is possible that individuals with ADHD show a diminished ability to control interference in more complex situations or tasks.

Open Access This article is distributed under the terms of the Creative Commons Attribution Noncommercial License which permits any noncommercial use, distribution, and reproduction in any medium, provided the original author(s) and source are credited.

\section{References}

Albrecht, B., Rothenberger, A., Sergeant, J., Tannock, R., Uebel, H., Banaschewski, T., et al. (2008). Interference control in attentiondeficit/hyperactivity disorder: Differential stroop effects for colour naming versus counting. Journal of Neural Transmission, 115, 241-247. doi:10.1007/s00702-007-0818-1.

Alderson, R. M., Rapport, M. D., \& Kofler, M. J. (2007). AttentionDeficit/Hyperactivity Disorder and behavioral inhibition: A meta- 
analytic review of the stop-signal paradigm. Journal of Abnormal Child Psychology, 35, 745-758. doi:10.1007/s10802-007-9131-6.

American Psychiatric Association (1994). Diagnostic and Statistical Manual of Mental Disorders (4th ed). American Psychiatric Press: Washington, DC.

Barkley, R. A. (1997). Behavioral inhibition, sustained attention and executive functions: Constructing a unifying theory of ADHD. Psychological Bulletin, 121, 65-94. doi:10.1037/0033-2909. 121.1.65.

Banaschewski, T., Ruppert, S., Tannock, R., Albrecht, B., Becker, A., Uebel, H., et al. (2006). Colour perception in ADHD. Journal of Child Psychology and Psychiatry, and Allied Disciplines, 47, 568-572. doi:10.1111/j.1469-7610.2005.01540.x.

Booth, J. E., Carlson, C. L., \& Tucker, D. M. (2007). Performance on a neurocognitive measure of alerting differentiates ADHD combined and inattentive subtypes: A preliminary report. Archives of Clinical Neuropsychology, 22, 423-432. doi:10.1016/j.acn. 2007.01.017.

Brodeur, D. A., \& Pond, M. (2001). The development of selective attention in children with attention deficit hyperactivity disorder. Journal of Abnormal Child Psychology, 29, 229-239. doi:10.1023/A:1010381731658.

Brus, B. T., \& Voeten, M. J. M. (1973). Een-minuuttest, vorm A en B, verantwoording en handleiding. Nijmegen: Berkhout.

Bush, G., Whalen, P. J., Rosen, B. R., Jenike, M. A., McInerney, S. C., Rauch, S. L., et al. (1998). The Counting Stroop: An interference task specialized for functional neuroimaging-validation study with functional MRI. Human Brain Mapping, 6, 270-282. doi:10.1002/(SICI)1097-0193(1998)6:4<270::AID-HBM6>3.0. $\mathrm{CO} ; 2-0$.

Bush, G., Frazier, J. A., Rauch, S. L., Seidman, L. J., Whalen, P. J., Jenike, M. A., et al. (1999). Anterior cingulate cortex dysfunction in attention-deficit/hyperactivity disorder revealed by fMRI and the counting stroop. Biological Psychiatry, 45, 1542-1552. doi:10.1016/S0006-3223(99)00083-9.

Bush, G., Spencer, T. J., Holmes, J., Shin, L. M., Valera, E. M., Seidman, L. J., et al. (2008). Functional magnetic resonance imaging of methylphenidate and placebo in attention- deficit/ hyperactivity disorder during the mulit-source interference task. Archives of General Psychiatry, 65, 102-114. doi:10.1001/ archgenpsychiatry.2007.16.

Carter, C. S., Krener, P., Chaderijan, M., Norhtcutt, C., \& Wolfe, V. (1995). Abnormal processing of irrelevant information in attention deficit hyperactivity disorder. Psychiatry Research, 56, 59-70. doi:10.1016/0165-1781(94)02509-H.

CGN, Het Corpus Gesproken Nederlands [Corpus Spoken Dutch]. Versie 1.0 (2004). Nederlandse taalunie.

Chhablidas, N., Pennington, B., \& Wilcutt, E. G. (2001). A comparison of the neuropsychological profiles of the DSM-IV subtypes of ADHD. Journal of Abnormal Child Psychology, 29, 529-540. doi:10.1023/A:1012281226028.

Crone, E. A., Jennings, J. R., \& Van Der Molen, M. W. (2003). Sensitivity to interference and response contigencies in attentiondeficit/hyperactivity disorder. Journal of Child Psychology and Psychiatry, and Allied Disciplines, 44, 214-226. doi:10.1111/ 1469-7610.00115.

Del' Homme, M., Kim, T. S., Loo, S. K., Yang, M. H., \& Smalley, S. L. (2007). Familial association and frequency of learning disabilities in ADHD sibling pair families. Journal of Abnormal Child Psychology, 35, 55-62.

Drechsler, R., Brandeis, D., Földényi, M., Imhof, K., \& Steinhausen, H. C. (2005). The course of neuropsychological functions in children with attention deficit hyperactivity disorder from late childhood to early adolescence. Journal of Child Psychology and Psychiatry, 46, 824-836.
Eriksen, C. W., \& Schultz, D. W. (1979). Information processing in visual search: A continuous flow conception and experimental results. Perception \& Psychophysics, 25, 249-263.

Fan, J., Flombaum, J. I., McCandliss, B. D., Thomas, K. M., \& Posner, M. I. (2003). Cognitive and brain consequences of conflict. NeuroImage, 18, 42-57.

Fassbender, C., \& Schweitzer, J. B. (2006). Is there evidence for neural compensation in attention deficit hyperactivity disorder? A review of the functional imaging literature. Clinical Psychology Review, 26, 445-465.

Fraizer, T. W., Demaree, H. A., \& Youngstrom, E. A. (2004). Metaanalysis of intellectual and neuropsychological test performance in attention-deficit/hyperactivity disorder. Neuropsychology, 18, 543-555.

Friedman, N. P., \& Miyake, A. (2004). The relations among inhibition and interference control functions: A latent-variable analysis. Journal of Experimental Psychology: General, 133, 101-135.

Hervey, A. S., Epstein, J. N., \& Curry, J. F. (2004). Neuropsychology of adults with attention- deficit/hyperactivity disorder: A metaanalytic review. Neuropsychology, 18, 485-503.

Homack, S., \& Riccio, C. A. (2004). A meta-analysis of the sensitivity and specificity of the stroop color and word test with children. Archives of Clinical Neuropsychology, 19, 725-743.

Jonkman, L. M., Kemner, C., Verbaten, M. N., Koelega, H. S., Camfferman, G., VanderGaag, R. J., et al. (1997). Event-related potentials and performance of attention-deficit hyperactivity disorder: Children and normal controls in auditory and visual selective attention tasks. Biological Psychiatry, 41, 595-611.

Jonkman, L. M., Kemner, C., Verbaten, M. N., Van Engeland, H., Kenemans, J. L., Camfferman, G., et al. (1999). Perceptual and response interference in children with attention-deficit hyperactivity disorder, and the effects of methylphenidate. Psychophysiology, 36, 419-429.

Kane, M. J., \& Engle, R. W. (2003). Working-memory capacity and the control of attention: The contributions of goal neglect, response competition, and task set to Stroop interference. Journal of Experimental Psychology: General, 132, 47-70.

Kaufman, L., \& Nuerk, H. C. (2006). Interference effects in a numerical stroop parardigm in 9- to 12-year old children with ADHD-C. Child Neuropsychology, 12, 223-243.

Kort, W., Compaan, E. L., Bleichrodt, N., Resing, W. C. M., Schittekatte, M., Bosman, M., et al. (2002). WISC-III. [Dutch translation of the Wechsler Intelligence Scales for Children, 3rd ed]. Amsterdam NL: NDC/NIP.

Konrad, K., Neufang, S., Hanisch, C., Fink, G. R., \& HerpetzDahlmann, B. (2006). Dysfunctional attentional networks in children with attention deficit/hyperactivity disorder: Evidence from an event-related functional magnetic resonance imaging study. Biological Psychiatry, 59, 643-651.

Lansbergen, M. M., Kenemans, J. L., \& Van Engeland, H. (2007). Stroop interference and attention-deficit/hyperactivity disorder: A review and meta-analysis. Neuropsychology, 21, 251-262.

Lijfijt, M., Kenemans, J. L., Verbaten, M. N., \& Van Engeland, H. (2005). A meta-analytic review of stopping performance in attention-deficit/hyperactivity disorder: Deficient inhibitory motor control? Journal of Abnormal Psychology, 114, 216-222.

MacLeod, C. M. (1991). Half a century of research on the Stroop effect: An integrative review. Psychological Bulletin, 109, 163203.

MacLeod, C. M., \& MacDonald, P. A. (2000). Interdimensional interference in the Stroop effect: Uncovering the cognitive and neural anatomy of attention. Trends in Cognitive Sciences, 4, 383-391.

Marchetta, N. D. J., Hurks, P. P. M., Krabbendam, L., \& Jolles, J. (2008). Interference control, working memory, concept shifting, 
and verbal fluency in adults with attention-deficit/hyperactivity disorder (ADHD). Neuropsychology, 22, 74-84.

Martinussen, R., Hayden, J., Hogg-Johnson, S., \& Tannock, R. (2005). A meta-analysis of working memory impairments in children with attention-deficit/hyperactivity disorder. Journal of the American Academy of Child and Adolescent Psychiatry, 44, 377-384.

McClain, L. (1983). Stimulus-response compatibility affects auditory stroop interference. Perception \& Psychophysics, 33, 266-270.

Oosterlaan, J., Logan, G. D., \& Sergeant, J. A. (1998). Response inhibition in $\mathrm{AD} / \mathrm{HD}, \mathrm{CD}$, comorbid $\mathrm{AD} / \mathrm{HD}+\mathrm{CD}$, anxious, and control children: A meta-analysis of studies with the stop task. Journal of Child Psychology and Psychiatry, 39, 411-425.

Oosterlaan, J., Scheres, A., Antrop, I., Roeyers, H., \& Sergeant, J. A. (2000). Vragenlijst voor Gedragsproblemen bij Kinderen (VvGK). Nederlandse bewerking van de Disruptive Behavior Disorders Rating Scale [Dutch translation of the Disruptive Behavior Disorders Rating Scale]. Lisse: Swets \& Zeitlinger.

Pelham, W. E., Gnagy, E. M., Greenslade, K. E., \& Milich, R. (1992). Teacher ratings of DSM-III-R symptoms for the disruptive behavior disorders. Journal of the American Academy of Child and Adolescent Psychiatry, 31, 210-218.

Pennington, B. F., \& Ozonoff, S. (1996). Executive functions and developmental psychopathology. Journal of Child Psychology and Psychiatry, 37, 51-87.

Peterson, B. S., Kane, M. J., Alexander, G. M., Lacadie, C., Skudlarski, P., Leung, H. C., et al. (2002). An event-related functional MRI study comparing interference effects in the Simon and Stroop tasks. Cognitive Brain Research, 13, 427-440.

Pritchard, V. E., Neumann, E., \& Rucklidge, J. J. (2007). Interference and negative priming effects in adolescents with attention deficit hyperactivity disorder. American Journal of Psychology, 120, 91-122.

Protopapas, A., Archonti, A., \& Skaloumbakas, C. (2007). Reading ability is negatively related to Stroop interference. Cognitive Psychology, 54, 251-282.

Rubia, K., Smith, A., \& Taylor, E. (2007). Performance of children with attention deficit hyperactivity disorder (ADHD) on a test battery of impulsiveness. Child Neuropsychology, 13, 276-304.

Scheres, A., Oosterlaan, J., \& Sergeant, J. A. (2001). Response execution and inhibition in children with $\mathrm{AD} / \mathrm{HD}$ and other disruptive disorders: The role of behavioural activation. Journal of Child Psychology and Psychiatry, 42, 347-357.

Scheres, A., Oosterlaan, J., Geurts, H. M., Morein-Zamir, S., Meiran, N., Schut, H., et al. (2004). Executive functioning in ADHD: Primarily and inhibition deficit? Archives of Clinical Neuropsychology, 19, 569-594.

Schulz, K. P., Tang, C. Y., Fan, J., Marks, D. J., Cheung, A. M., Newcorn, J. H., et al. (2005). Differential prefrontal cortex activation during inhibitory control in adolescents with and without childhood attention-deficit/hyperactivity disorder. Neuropsychology, 19, 390-402.

Schwartz, K., \& Verheaghen, P. (2008). ADHD and Stroop interference from age 9 to age 41years: A meta-analysis of developmental effects. Psychological Medicine, 29, 1-10.

Seidman, L. J., Valera, E. M., Makris, N., Monuteaux, M. C., Boriel, D. L., Kelkar, K., et al. (2006). Dorsolateral prefrontal and anterior cingulate cortex volumetric abnormalities in adults with attention-deficit/hyperactivity disorder identified by magnetic resonance imaging. Biological Psychiatry, 60, 1071-1080.

Sergeant, J. A. (2005). Modeling attention-deficit/hyperactivity disorder: A critical appraisal of the cognitive-energetic model. Biological Psychiatry, 57, 1248-1255.

Sergeant, J. A., Oosterlaan, J., \& Van Der Meere, J. J. (1999). Information processing and energetic factors in attention-deficit/ hyperactivity disorder. In H. C. Quay, \& A. E. Hogan (Eds.), Handbook of disruptive behavior disorders (pp. 75-104). New York: Plenum Press.

Shaffer, D., Fisher, P., Lucas, C. P., Dulcan, M. K., \& Schwab-Stone, M. E. (2000). NIMH Diagnostic Interview Schedule for Children Version IV (NIMH DISC- IV): description, differences from previous versions, and reliability of some common diagnoses. Journal of the American Academy of Child and Adolescent Psychiatry, 39, 28-38.

Simon, J. R. (1990). The effect of an irrelevant directional cue on human information processing. In R. Proctor, \& T. Reeve (Eds.), Stimulus-Response compatibility: An integrated perspective (pp. 31-88). Amsterdam: North-Holland.

Smith, A. B., Taylor, E., Brammer, M., Toone, B., \& Rubia, K. (2006). Task-specific hypoactivation in prefrontal and temporoparietal brain regions during motor inhibition and task switching in medication-naïve children and adolescents with attention deficit hyperactivity disorder. American Journal of Psychiatry, 163, 1044-1051.

Sonuga-Barke, E. J. S. (2003). The dual pathway model of AD/HD: An elaboration of neuro- developmental characteristics. Neuroscience and BioBehavioral Reviews, 27, 593-604.

Stins, J. F., Polderman, J. C., Boonsma, D. I., \& De Geus, E. J. C. (2005). Response interference and working memory in 12-year old children. Child Neuropsychology, 11, 191-201.

Stroop, J. R. (1935). Studies of interference in serial verbal reactions. Journal of Experimenta Psychology, 18, 643-662.

Tannock, R., Martinussen, R., \& Frijters, J. (2000). Naming speed performance and stimulant effects indicate effortful, semantic processing deficits in attention-deficit/hyperactivity disorder. Journal of Abnormal Child Psychology, 28, 237-252.

Vaidya, C. J., Bunge, S. A., Dudokovic, B. A., Zalecki, M. A., Elliot, G. R., Gabrieli, J. D. E., et al. (2005). Altered neural substrates of cognitive control in childhood ADHD: Evidence from functional magnetic resonance imaging. American Journal of Psychiatry, $162,1605-1613$.

Van Meel, C. S., Heslenfeld, D. J., Oosterlaan, J., \& Sergeant, J. A. (2007). Adaptive control deficits in attention-deficit/hyperactivity disorder (ADHD): The role of error processing. Psychiatry Research, 151, 211-220.

Van Mourik, R., Oosterlaan, J., \& Sergeant, J. A. (2005). The stroop revisited: A meta-analysis of interference control in $\mathrm{AD} / \mathrm{HD}$. Journal of Child Psychology and Psychiatry, 46, 150-165.

Van Mourik, R., Oosterlaan, J., Heslenfeld, D. J., Konig, C., \& Sergeant, J. A. (2007). When distraction is not distracting: A behavioral and ERP study on distraction in ADHD. Journal of Clinical Neurophysiology, 118, 1855-1865.

Weschler, D. (1991). Weschler Intelligence Scales for Children (3rd ed.). San Antonio, TX: The Psychological Corporation.

Wiersema, R., Van der Meere, J., Roeyers, H., Van Coster, R., \& Baeyens, D. (2006). Event rate and event-related potentials in ADHD. Journal of Child Psychology and Psychiatry, 47, 560 567.

Willcutt, E., Sonuga-Barke, E. J. S., Nigg, J. T., \& Sergeant, J. A. (2008). Recent developments in neuropsychological models of childhood psychiatric disorders. In T. Banaschewski, \& L. A. Rohde (Eds.), Advances in biological psychiatry: Vol. 24. Biological child psychiatry. Recent trends and developments (pp. 195-226). Basel: Karger.

Zang, Y. F., Jin, Z., Weng, X. C., Zhang, L., Zeng, Y. W., Yang, L., et al. (2005). Functional MRI in attention-deficit hyperactivity disorder: Evidence for hypofrontality. Brain \& Development, $27,544-550$. 